\title{
The influence of phylogeny on posttranscriptional modification of rRNA in thermophilic prokaryotes: The complete modification map of $16 \mathrm{~S}$ rRNA of Thermus thermophilus*
}

Rebecca Guymon, ${ }^{\ddagger}$ Steven C. Pomerantz, ${ }^{\ddagger}$ Pamela F. Crain ${ }^{\ddagger}$ and James A. McCloskey ${ }^{\ddagger}$

\section{Supporting Information}

Table S1. Assignments for monomer mass fragment ions used for detection of modified residues in RNase digest oligonucleotides

\begin{tabular}{|c|c|c|}
\hline Nucleoside & $m / z$ & assignment $^{\mathrm{a}}$ \\
\hline \multirow{3}{*}{$m^{7} G, m^{2} G$} & 164 & mGua \\
\hline & 358 & $m G>p$ \\
\hline & 376 & $\mathrm{mGp}$ \\
\hline \multirow{2}{*}{$\mathrm{m}_{2}^{2} \mathrm{G}$} & 178 & $\mathrm{~m}_{2} \mathrm{Gua}$ \\
\hline & 372 & $\mathrm{~m}_{2} \mathrm{G}>\mathrm{p}$ \\
\hline \multirow{4}{*}{$\Psi$} & 225 & $\Psi-\mathrm{H}_{2} \mathrm{O}$ \\
\hline & 207 & $\Psi-2 \mathrm{H}_{2} \mathrm{O}$ \\
\hline & 189 & $207-\mathrm{H}_{2} \mathrm{O}$ \\
\hline & 164 & 207 - HNCO \\
\hline \multirow{3}{*}{$\mathrm{m}_{2}^{6} \mathrm{~A}$} & 162 & $\mathrm{~m}_{2} \mathrm{Ade}$ \\
\hline & 356 & $\mathrm{~m}_{2}^{6} \mathrm{~A}>\mathrm{p}$ \\
\hline & 374 & $\mathrm{~m}_{2}^{6} \mathrm{Ap}$ \\
\hline \multirow{2}{*}{$\mathrm{m}^{5} \mathrm{C}$} & 124 & mCyt \\
\hline & 336 & $\mathrm{mCp}$ \\
\hline \multirow{3}{*}{$\mathrm{m}^{4} \mathrm{Cm}$} & 124 & mCyt \\
\hline & 332 & $\mathrm{mCm}>\mathrm{p}$ \\
\hline & 350 & $\mathrm{mCmp}$ \\
\hline
\end{tabular}




\begin{tabular}{|c|l|l|}
\hline $\mathrm{Cm}$ & 398 & $\mathrm{pCm}>\mathrm{p}$ \\
\hline \multirow{3}{*}{$\mathrm{m}^{3} \mathrm{U}$} & 125 & $\mathrm{mUra}$ \\
& 319 & $\mathrm{mU}>\mathrm{p}$ \\
& 337 & $\mathrm{mUp}$ \\
\hline
\end{tabular}

${ }^{a}$ All are singly charged negative ions

Fig. S1

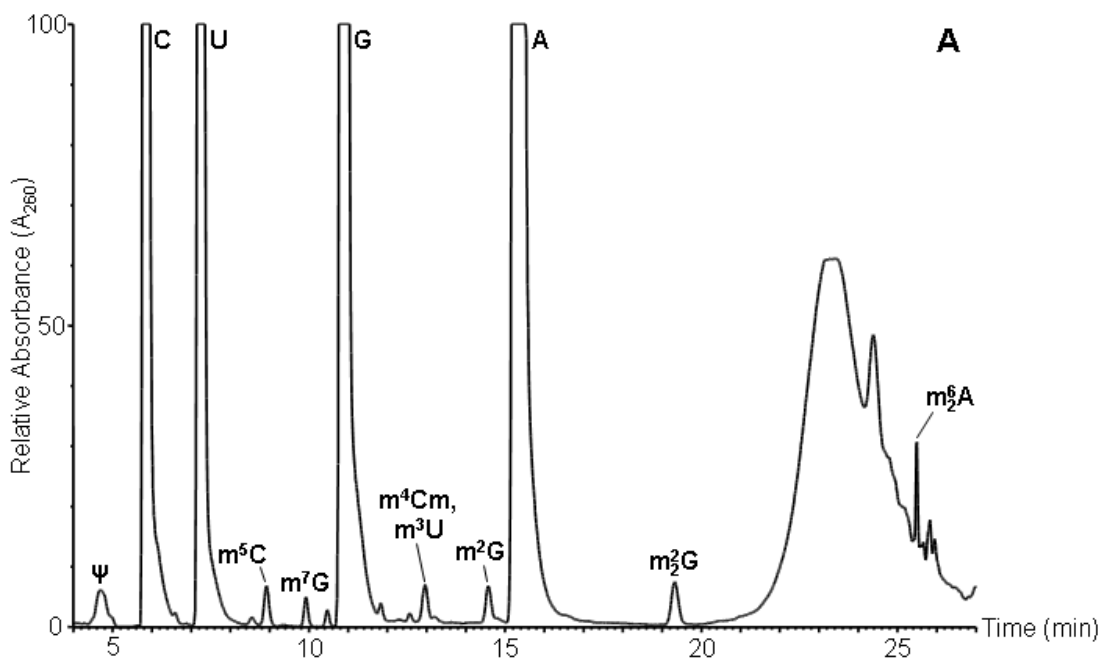

FIGURE S1. Census of modified nucleosides in Thermus thermophilus 16S rRNA by LC/MS analysis of a total nucleoside digest. 
Fig. S2

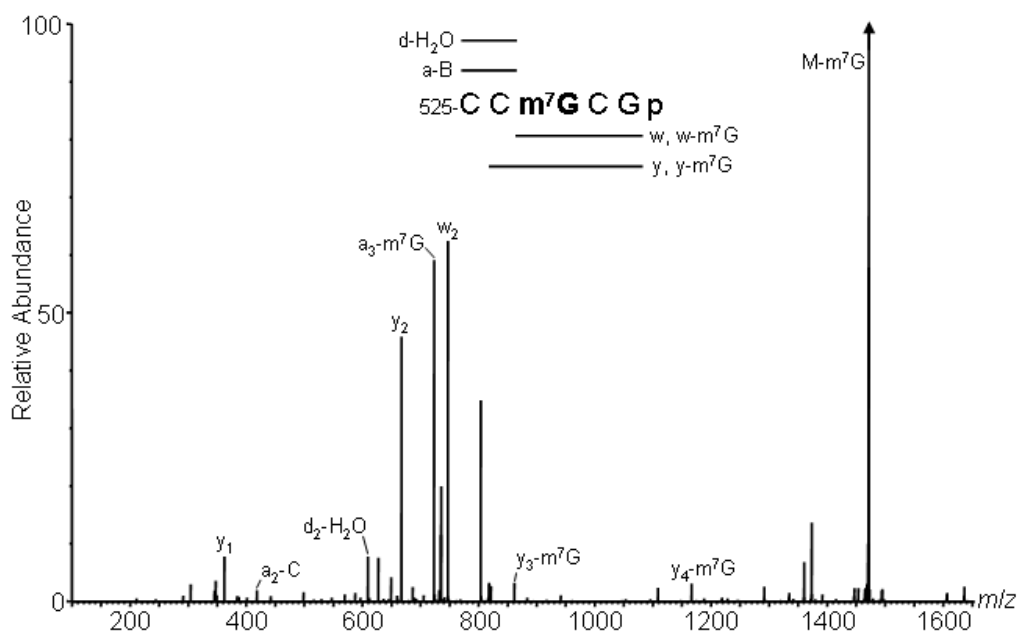

FIGURE S2. Mass spectrum from CID of 525-CCm ${ }^{7} \mathrm{GCGp}$. 
Fig. S3

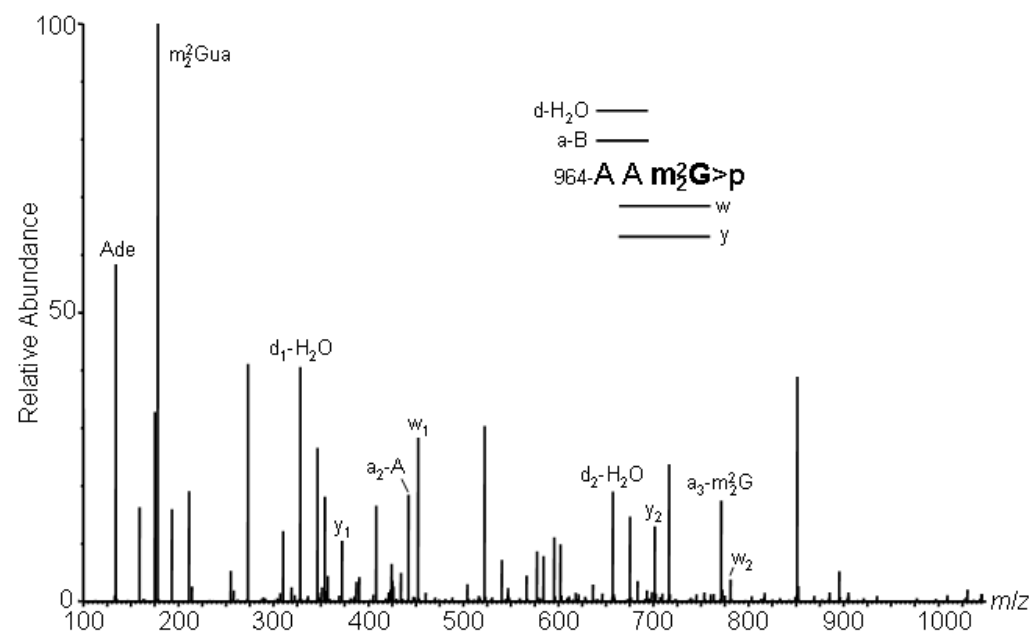

FIGURE S3. Mass spectrum from CID of $964-\mathrm{AAm}_{2}^{2} \mathrm{G}>\mathrm{p}$, with sequence ions annotated, for placement of $\mathrm{m}_{2}^{2} \mathrm{G}-966$. 


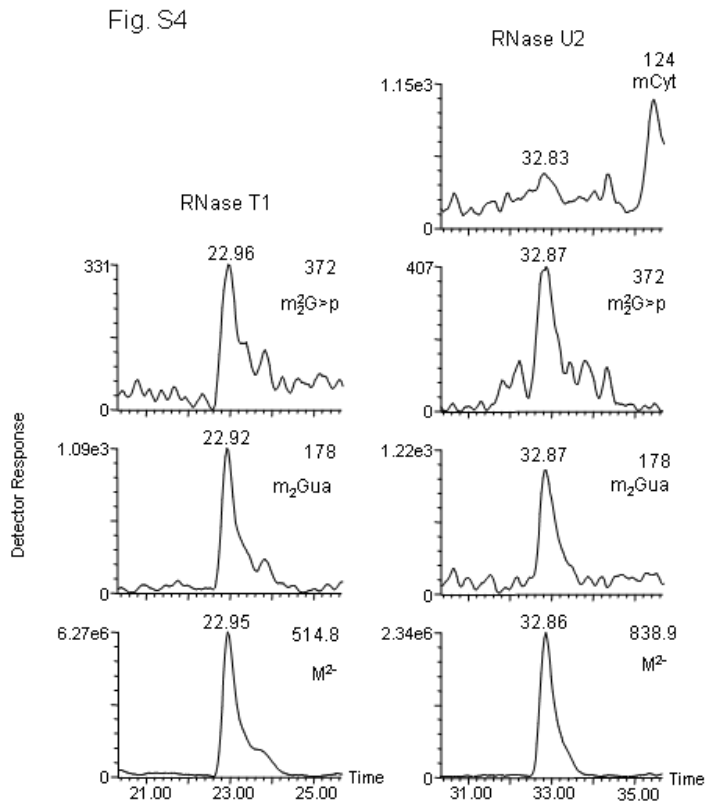

FIGURE S4. Chromatographic time alignments between characteristic low-mass ions and molecular ions in RNase T1 and U2 digests used for placement of adjacent modifications $\mathrm{m}_{2}^{2} \mathrm{G}-966$ and $\mathrm{m}^{5} \mathrm{C}-967$. 


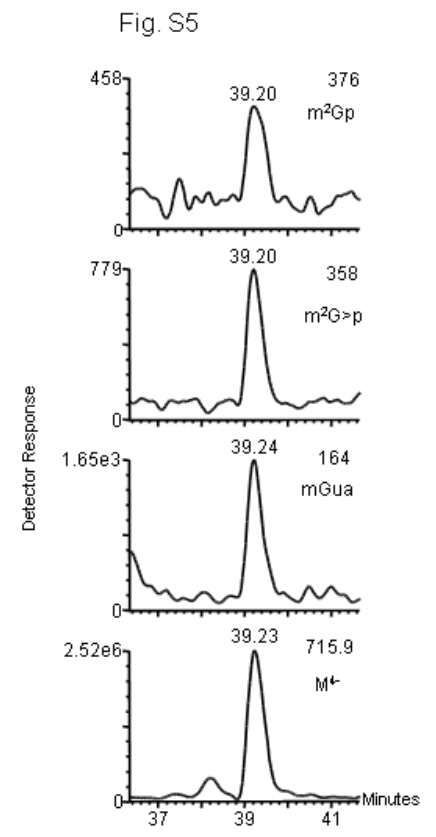

FIGURE S5. Chromatographic time alignments between methylguanine fragment ions and the molecular ion from $\mathrm{U} 2$ product $M_{\mathrm{r}} 2866$, identifying the 1205-1213 oligonucleotide as containing $\mathrm{m}^{2} \mathrm{G}$. 
Fig. S6

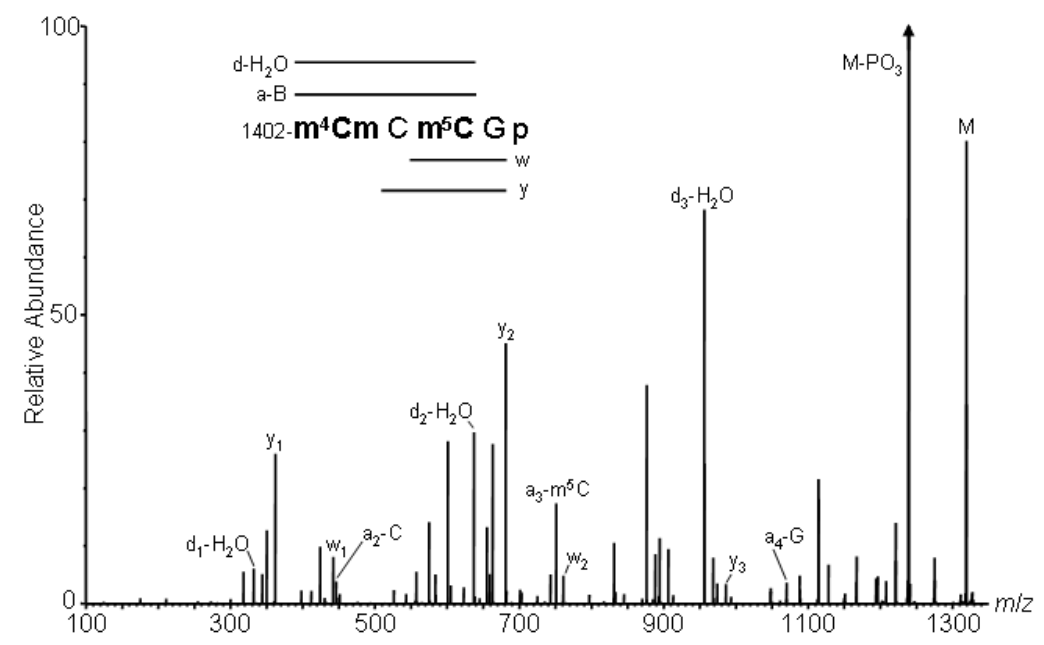

FIGURE S6. Mass spectrum from CID of RNase T1 oligonucleotide $M_{\mathrm{r}} 1320$ (1402$\mathrm{m}^{4} \mathrm{CmCm}^{5} \mathrm{CGp}$ ), showing sequence ions used for distribution of three methyls in residues 1402 and 1404. 
Fig. $\$ 7$

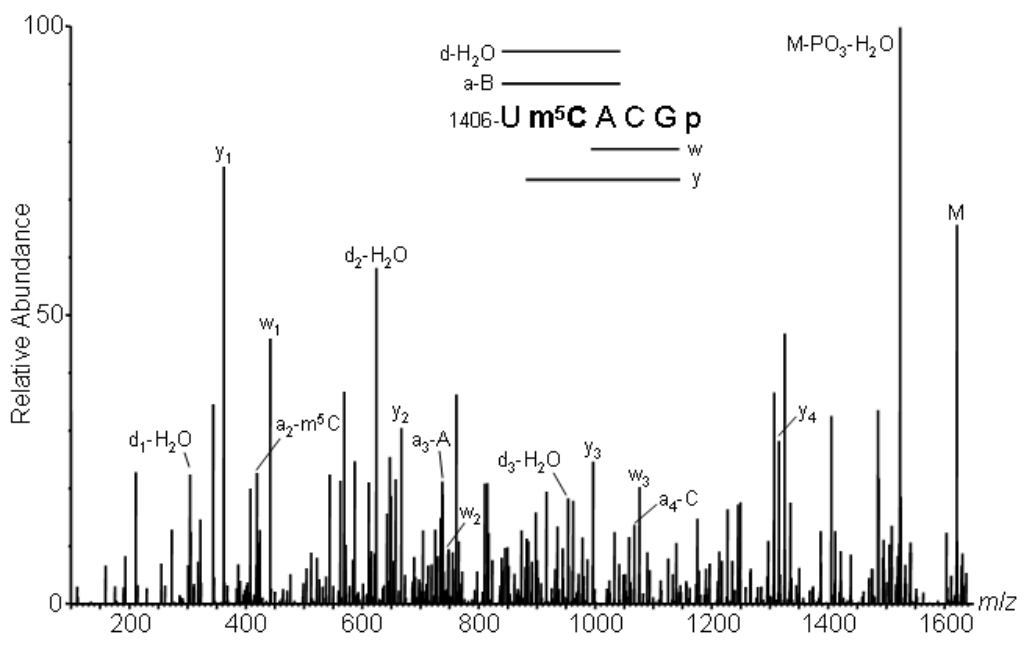

FIGURE S7. Mass spectrum from CID of RNase T1 oligonucleotide $M_{\mathrm{r}} 1622$ (1406$\mathrm{Um}^{5} \mathrm{CACG}$ ), showing position of $\mathrm{m}^{5} \mathrm{C}-1407$ within the heavily methylated segment shown in Figure 6. 
Fig. S8

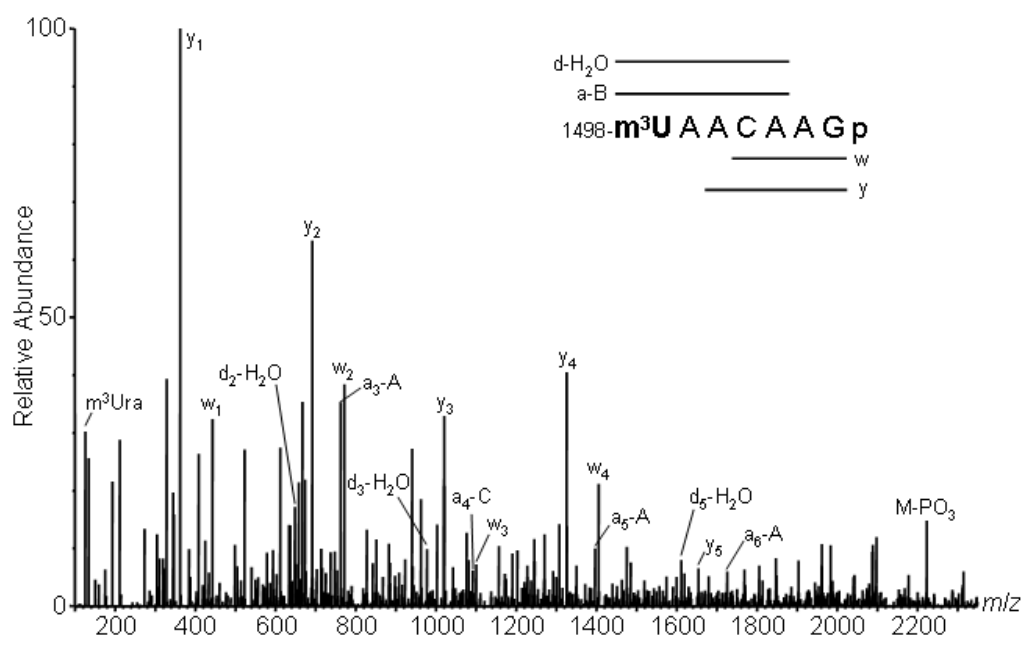

FIGURE S8. Mass spectrum from CID of RNase T1 oligonucleotide $M_{\mathrm{r}} 2304$ (1498$\mathrm{m}^{3} \mathrm{UAACAAGp}$ ), showing sequence ions consistent with placement of base-methylated uridine at the 5 ' terminus of the oligonucleotide. 
Fig. S9

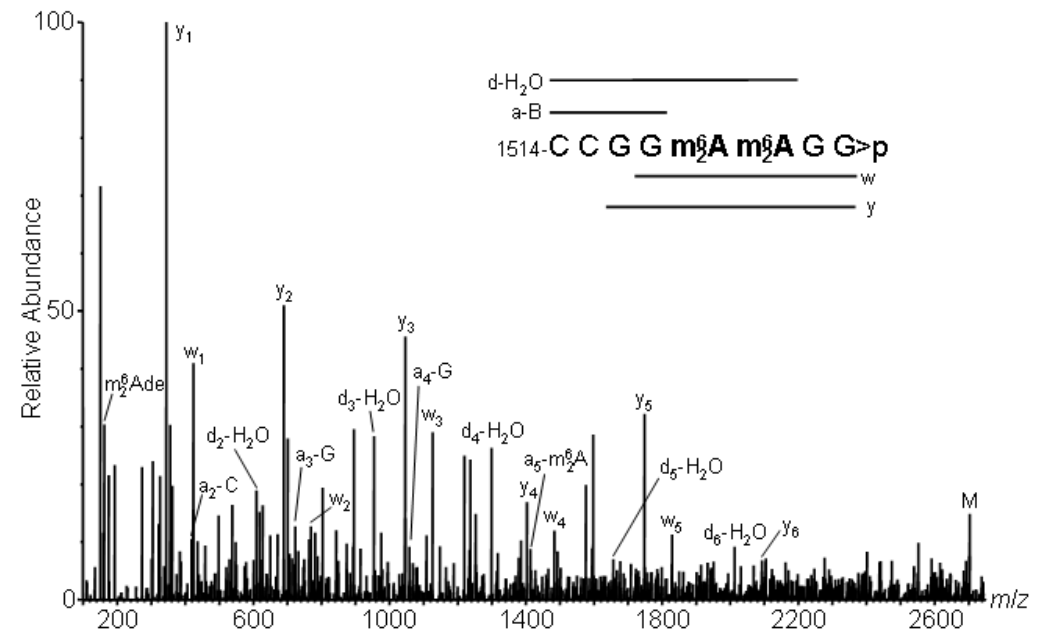

FIGURE S9. Mass spectrum following CID of RNase U2 oligonucleotide $M_{\mathrm{r}} 2704$, confirming placement of the highly conserved tandem $\mathrm{m}_{2}^{6} \mathrm{~A}$ residues in the loop of helix 45. 
Fig. S10

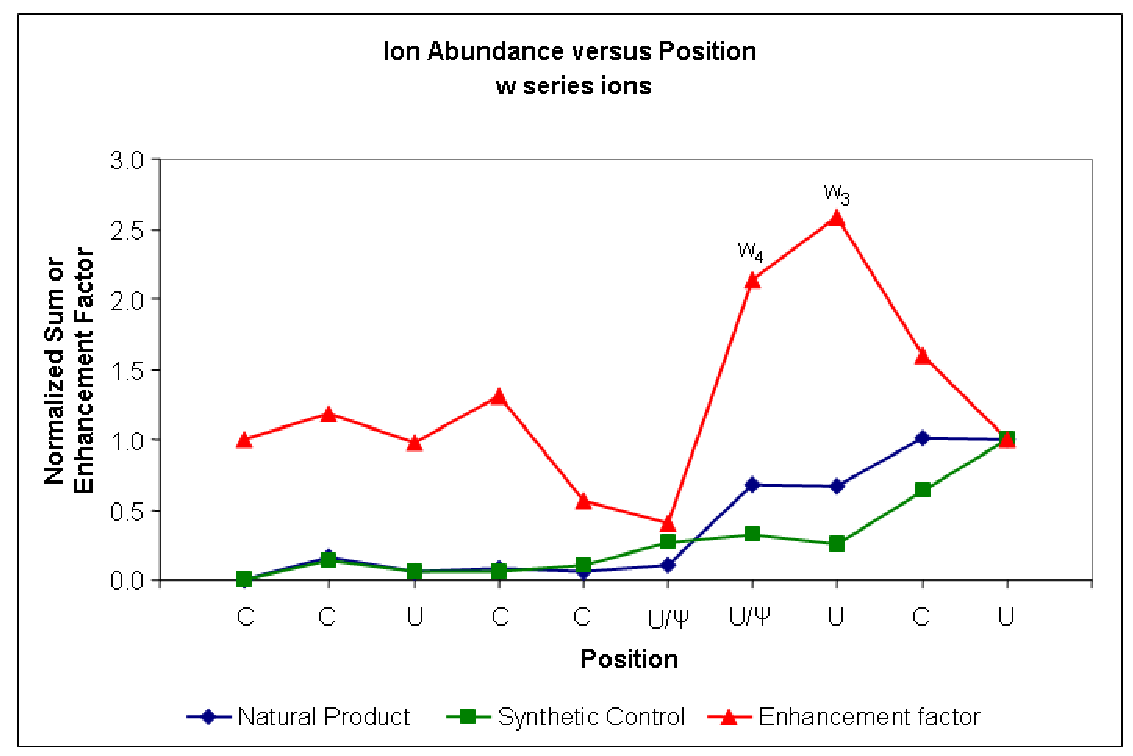

FIGURE S10. Normalized sum, encompassing all observed charge states, of the $\mathbf{w}$ series of sequence ions from the mass spectrum of RNase U2 oligonucleotide $M_{\mathrm{r}} 2993$, compared with unmodified control oligonucleotide. Enhancement factors (ref 30) for ions $\mathbf{w}_{\mathbf{3}}$ and $\mathbf{w}_{\mathbf{4}}$ result from pseudouridylation of residues six and seven. 